\title{
Site effects and site amplification due to the 2009 Abruzzo earthquake
}

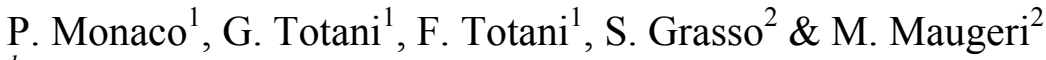 \\ ${ }^{1}$ Department of Structural, Water and Soil Engineering, \\ University of L'Aquila, Italy \\ ${ }^{2}$ Department of Civil and Environmental Engineering, \\ University of Catania, Italy
}

\begin{abstract}
This paper presents the results of numerical analyses carried out to assess the different seismic response of two sites in the urban area of L'Aquila, selected as representative of typical subsoil conditions in the old city centre and in the recently developed suburban Pettino district. Both areas were severely damaged by the April 6, 2009 earthquake. The geotechnical model of the subsoil at each of the two sites and the related parameters, defined based on accurate site investigations, are described. The comparison of results of seismic response analyses at the two sites, in agreement with strong motion recordings of the April 6, 2009 main shock, confirms that site effects due to different subsoil conditions played an important role in the observed non-uniform damage distribution. Particularly in the city centre, characterized by an inversion of the shear wave velocity $V_{\mathrm{S}}$ with depth, the simplified approach based on elastic response spectra defined according to ground type $\left(V_{\mathrm{S}, 30}\right)$ of the Italian building code tends to underestimate the seismic action and should be used with caution.
\end{abstract}

Keywords: site seismic response analysis, site effects, L'Aquila 2009 earthquake.

\section{Introduction}

The April 6, 2009 Abruzzo earthquake $\left(M_{\mathrm{L}}=5.8, M_{\mathrm{W}}=6.3\right)$ caused considerable damage to structures over an area of approximately 600 square kilometres, including the city of L'Aquila (MCS Intensity I = VIII-IX) and several villages of the middle Aterno River valley. A maximum MCS Intensity I = IX-X was experienced at Onna and Castelnuovo. Even for similar types of buildings the 
distribution of damage within the affected area was irregular, creating speculation for both rupture directivity and site amplification effects.

Soon after the earthquake evaluations of site effects (GEER Working Group [1]) were obtained from the available strong motion recordings in the epicentral area, including the city of L'Aquila. In the middle Aterno River valley, where such recordings were not available, a preliminary assessment of site effects was carried out based on the survey of the variable damage distribution (in nearby villages, or within the same village), which was related to geological and morphological conditions, accounting for the different types of buildings.

In the following months quantitative evaluations of site effects based on numerical site response analyses were made available, as a result of a comprehensive seismic microzonation project of the area of L'Aquila, entrusted by the Italian Department of Civil Protection (MS-AQ Working Group [2]).

In this paper the attention is focused on site effects in the urban area of L'Aquila. In particular, two zones of significant interest are considered: (a) the old city centre of L'Aquila, which includes most of the historical heritage and several old masonry buildings, heavily damaged by the main shock, and (b) the area of Pettino, a recently developed suburban residential district located NW of the city centre, also affected by considerable damage, where most buildings are 3-6 storey reinforced concrete frame structures. The paper presents the results of numerical analyses carried out to assess the different seismic response of two test sites (Figure 1), one located in the city centre (Palazzo Camponeschi) and one in the Pettino district (Via Sila Persichelli), selected as representative of the typical subsoil conditions in each of the two examined areas.

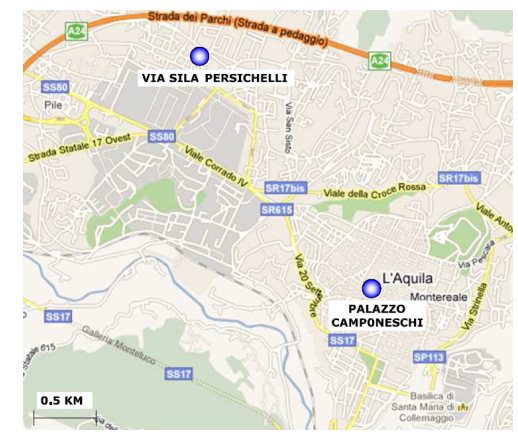

Figure 1: $\quad$ Location of the two test sites in the area of L'Aquila.

\section{Subsoil conditions in the urban area of L'Aquila}

The subsoil conditions in the urban area of L'Aquila were reconstructed based on geological information and on a large amount of results of geotechnical and geophysical investigations executed in the area of L'Aquila in the period 20092011, in particular for the seismic microzonation project (MS-AQ Working Group [2]) and for ongoing research at the University of L'Aquila, Centre for Research and Education in Earthquake Engineering (CERFIS). 
The site investigation data base includes borehole logs, in situ measurements of shear wave velocity $V_{\mathrm{S}}$ by various techniques (Down-Hole, Cross-Hole, surface wave tests, seismic dilatometer) and seismic noise measurements. In particular this study is largely based on $V_{\mathrm{S}}$ profiles obtained in situ by seismic dilatometer (SDMT). The SDMT test procedure and interpretation are described by Marchetti et al. [3]. A comprehensive review of SDMT results obtained in the area of L'Aquila following the April 6, 2009 earthquake can be found in Amoroso et al. [4]. Due to the characteristics of the soils commonly encountered in this area (mostly coarse-grained, non-penetrable), SDMT measurements $\left(V_{\mathrm{S}^{-}}\right.$ only) were generally executed in backfilled boreholes, according to the procedure devised by Totani et al. [5].

The subsoil conditions in the urban area of L'Aquila are quite complex. In the city centre (Figure 2a) the upper portion of the subsoil is constituted by the deposit known as "Brecce dell'Aquila" (fine to coarse calcareous fragments of variable size, mostly of some centimetres, embedded in sandy or silty matrix, characterized by highly variable cementation and mechanical properties), $\approx 80$ $100 \mathrm{~m}$ thick, where generally $V_{\mathrm{S}} \approx 600-1000 \mathrm{~m} / \mathrm{s}$. The breccias are superimposed to fine- to medium-grained, mostly silty lacustrine deposits of average thickness $\approx 250-270 \mathrm{~m}$, where $V_{\mathrm{S}} \approx 400$ to $600-700 \mathrm{~m} / \mathrm{s}$, placed on the bedrock (limestone). Gravimetric investigations (MS-AQ Working Group [2]), confirmed directly by a $300 \mathrm{~m}$ deep borehole in Piazza Duomo (Amoroso et al. [6]), indicate that the top surface of the bedrock in the city centre is located below $300 \mathrm{~m}$ depth.

The area of Pettino, NW of the city centre (Figure 2b), is mostly characterized by the presence of coarse-grained debris materials (calcareous gravel in sandy silty matrix), having $V_{\mathrm{S}} \approx 600-1000 \mathrm{~m} / \mathrm{s}$, placed on the lacustrine deposits (here of very small thickness) or directly on the calcareous bedrock. The gravel layer is frequently covered with soft silty-clayey sediments of variable thickness (maximum $\approx 10-15 \mathrm{~m}$ ), generally having $V_{\mathrm{S}} \approx 200-300 \mathrm{~m} / \mathrm{s}$.

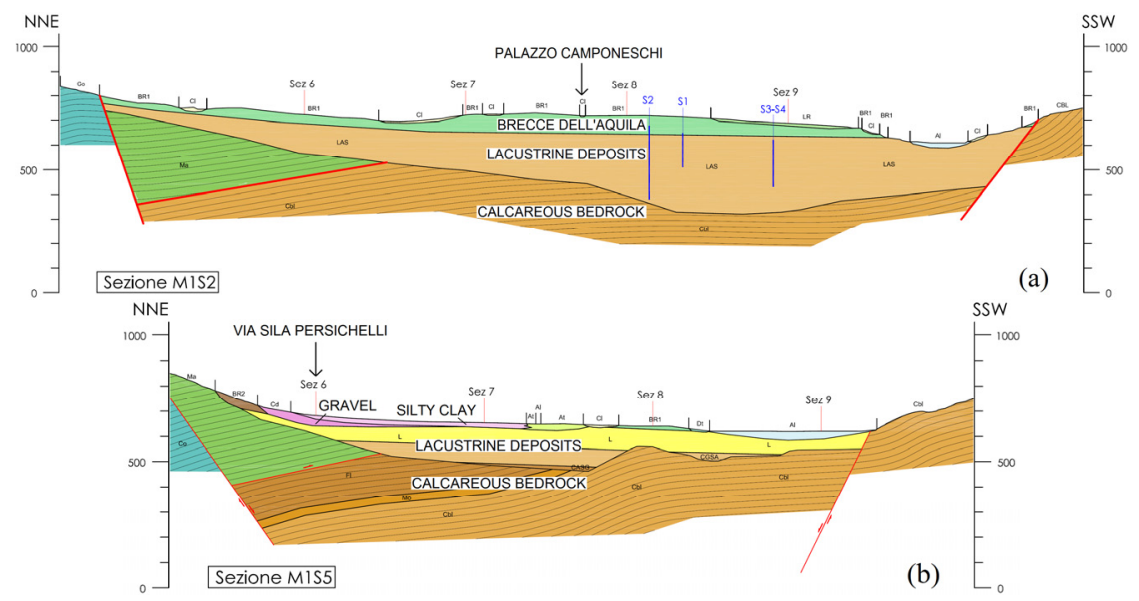

Figure 2: $\quad$ Schematic geological sections across (a) the city centre of L'Aquila, and (b) the Pettino area (modified after MS-AQ working group [2]). 
The above schematic description highlights substantially different subsoil conditions in the two areas. Basically, in the city centre the subsoil is characterized by an inversion of the shear wave velocity with depth, at the transition from the breccias to the lacustrine silts, and the bedrock (geological and seismic) is over $300 \mathrm{~m}$ deep. In contrast in the area of Pettino the shear wave velocity increases with depth and the seismic bedrock $\left(V_{\mathrm{S}}>800 \mathrm{~m} / \mathrm{s}\right)$ is frequently encountered at $\approx 20 \mathrm{~m}$ depth or less. Also, significant contrasts of $V_{\mathrm{S}}$ may be detected at the shallow contact silty clay/gravel. Such dissimilar pattern was confirmed by a large number of seismic noise measurements carried out for the seismic microzonation (MS-AQ Working Group [2]). In the city centre these measurements clearly identified, in the $\mathrm{H} / \mathrm{V}$ spectral ratio, the presence of a peak of $f_{0}$ (frequency of the first significant amplification peak) at $0.5-0.6 \mathrm{~Hz}$, corresponding to the top surface of the deep calcareous bedrock. (Low-frequency amplification effects in L'Aquila city centre had already been signaled by De Luca et al. [7]). In the area of Pettino amplification peaks were frequently observed between 3 and 7-8 Hz, suggesting contrasts of $V_{\mathrm{S}}$ at shallow depth.

\section{Numerical site response analysis method and seismic input}

\subsection{Method of analysis}

Numerical analyses of seismic response at the two selected sites were carried out using a 1D linear equivalent model, as implemented in the computer code EERA (Bardet et al. [8]). It is recognized that 2D or 3D effects may have played an important role in the non-uniform amplification effects observed at different sites (as well as many other factors, e.g. vertical component of ground motion, directivity effects, etc.). However, as a first approximation, the simple 1D model was assumed adequate to compare different responses of the two examined sites.

\subsection{Seismic input data}

The ground motion input data used in the numerical analyses include six different accelerograms applied at the bedrock (Figure 3). Five of these accelerograms were defined for the seismic microzonation of the area of L'Aquila (MS-AQ Working Group [2]): (NTC-08) compatible with the uniform hazard response spectrum (UHS) of the Italian building code, (PROB) compatible with the UHS spectrum obtained by probabilistic seismic hazard assessment, (DET_1, DET_2 and DET_3) obtained using a deterministic approach. The sixth (natural) accelerogram was selected from the Italian strong motion data base (http://itaca.mi.ingv.it) by use of strict criteria, e.g. source characteristics, ground type at the recording station, magnitude, distance from the source, maximum horizontal acceleration expected at the site. The selected accelerogram (UM) is the strong motion (EW component) recorded at the Assisi station during the September 26, 1997 Umbria-Marche earthquake $\left(M_{\mathrm{w}}=6\right.$, on outcrop, normal fault, site-source distance $\approx 20 \mathrm{~km}$ ), scaled to a peak ground acceleration similar to the other five accelerograms (scaling factor $\approx 2$ ). 

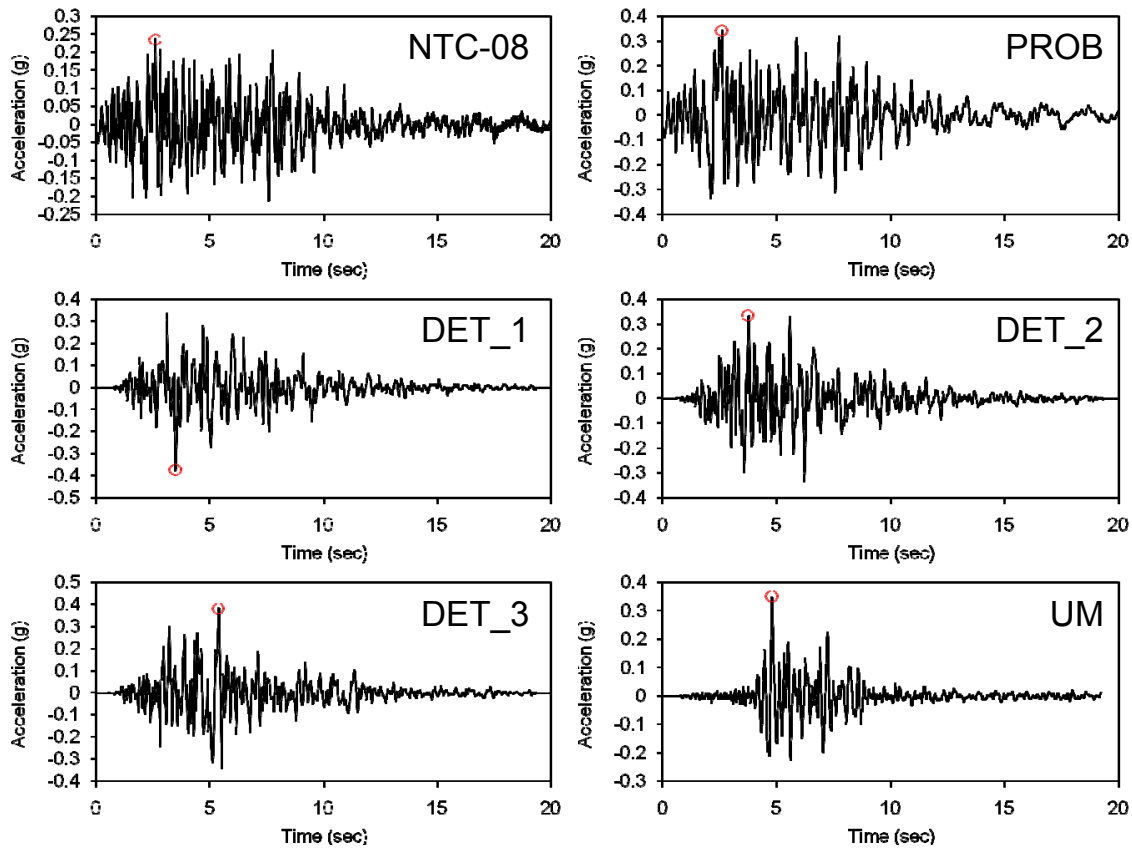

Figure 3: $\quad$ Input accelerograms used in site seismic response analyes.

\section{Site response analysis in L'Aquila city centre}

\subsection{Input soil data}

The geotechnical model of the subsoil at the site of Palazzo Camponeschi (L'Aquila city centre), including the soil parameters used in the numerical analyses, is schematized in Figure 4. The subsoil was modelled as a two-layer system: an upper $80 \mathrm{~m}$ thick coarse-grained layer (breccias), having $V_{\mathrm{S}}$ generally $>800-1000 \mathrm{~m} / \mathrm{s}$, and a lower $270 \mathrm{~m}$ thick fine-grained layer (lacustrine silts) having $V_{S} \approx 600-700 \mathrm{~m} / \mathrm{s}$, placed on the calcareous bedrock (350 $\mathrm{m} \mathrm{depth).}$

The profile of $V_{\mathrm{S}}$ in the breccias was defined as an average of five $V_{\mathrm{S}}$ profiles obtained by SDMT in backfilled boreholes to $74 \mathrm{~m}$ depth (Figure 5). In the lower lacustrine silts, in absence of direct measurements to this depth, the profile of $V_{\mathrm{S}}$ was defined as an average of $V_{\mathrm{S}}$ estimated as a function of depth or stress level by the experimental relationships by Chiara [9] and Crespellani et al. [10]. Such $V_{\mathrm{S}}$ profile is in reasonable agreement with $V_{\mathrm{S}}$ measured by Cross-Hole (Cardarelli and Cercato [11]) and by SDMT (Amoroso et al. [4]) at sites located at a lower elevation at the border of L'Aquila city centre (Ponte Rasarolo Aterno River, Fontana 99 Cannelle), where the top of the same lacustrine formation was encountered near the ground surface. The calcareous bedrock was characterized by $V_{\mathrm{S}}=1250 \mathrm{~m} / \mathrm{s}$, derived from a Cross-Hole test executed at the site of the strong motion station AQV (a few km West of the city centre), where the bedrock was found at $\approx 50 \mathrm{~m}$ depth (Di Capua et al. [12]). 


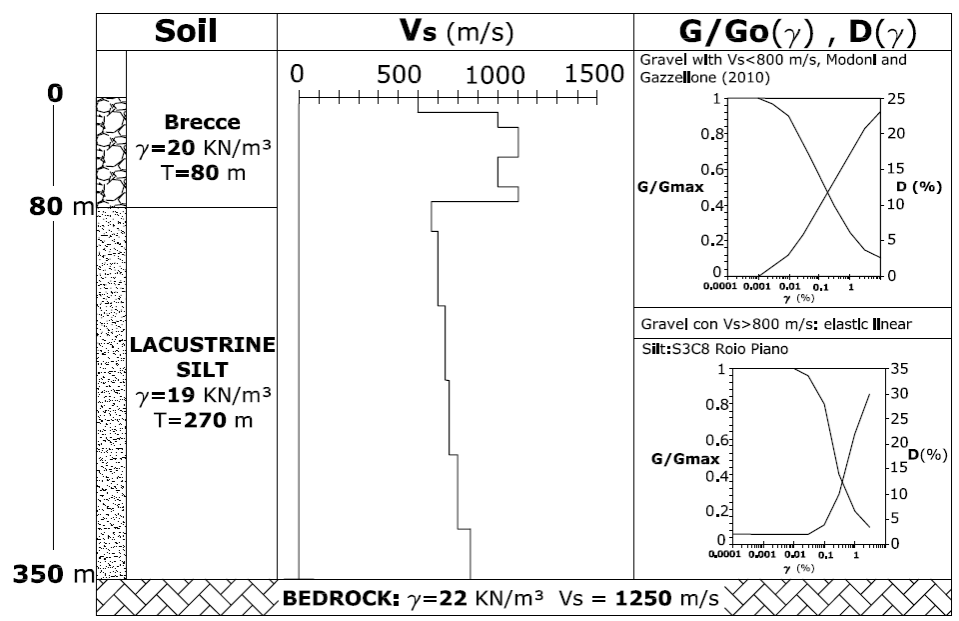

Figure 4: Geotechnical model of the subsoil and soil parameters for 1D seismic response analysis at the site of Palazzo Camponeschi.

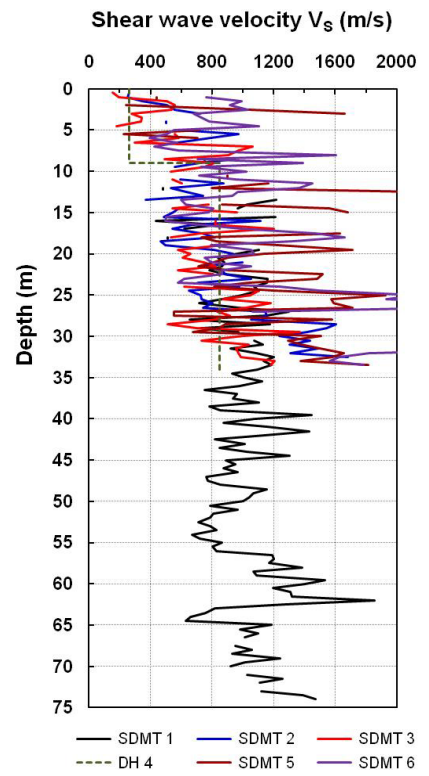

Figure 5: Profiles of shear wave velocity $V_{\mathrm{S}}$ obtained by SDMT (in backfilled boreholes) and Down-Hole (DH) at the site of Palazzo Camponeschi.

A specific difficulty in characterizing the non-linear and dissipative soil behaviour for seismic response analyses in the city centre of L'Aquila is the lack of laboratory curves of the normalized shear modulus $G / G_{0}$ and damping ratio $D$ versus shear strain $\gamma$ (undisturbed sampling is impossible in the breccias and 
prohibitive in the lower very deep lacustrine silts). In absence of specific $G / G_{0}-\gamma$ and $D-\gamma$ laboratory curves at the site of Palazzo Camponeschi, in the breccias literature $G / G_{0}-\gamma$ and $D-\gamma$ curves, proposed by Modoni and Gazzellone [13] for dense gravel, were assumed in the upper $10 \mathrm{~m}$ (weakly cemented, $V_{S} \approx 600 \mathrm{~m} / \mathrm{s}$ ). Between 10 and $80 \mathrm{~m}$ (higher cementation, $V_{S}>1000 \mathrm{~m} / \mathrm{s}$ ) the soil behaviour was assumed as linear elastic, as a first approximation. The lacustrine silt was characterized by $G / G_{0}-\gamma$ and $D-\gamma$ laboratory curves obtained by resonant column/torsional shear tests carried out at the University of Naples Federico II on an undisturbed sample (S3C8) taken in the same lacustrine formation, at $50 \mathrm{~m}$ depth, in the C.A.S.E. Project site of Roio Piano (MS-AQ Working Group [2]).

\subsection{Results and comparisons}

Figure 6 shows the comparison of the elastic acceleration response spectra resulting from the numerical analysis using six different input accelerograms, the corresponding average spectrum and the elastic response spectrum defined according to the simplified approach of the Italian building code (NTC 2008 [14]), for a reference return period $T_{R}=475$ years and type B ground. It can be noted in Figure 6 that the spectral acceleration $S_{\mathrm{a}}$ calculated by the numerical analysis (average of the six input accelerograms) is generally higher than $S_{\text {a }}$ calculated according to NTC 2008 [14] in the range of periods $T \approx 0.2-0.4 \mathrm{~s}$, similar to the fundamental period of many old masonry buildings located in L'Aquila city centre. For all the input accelerograms the diagram exhibits

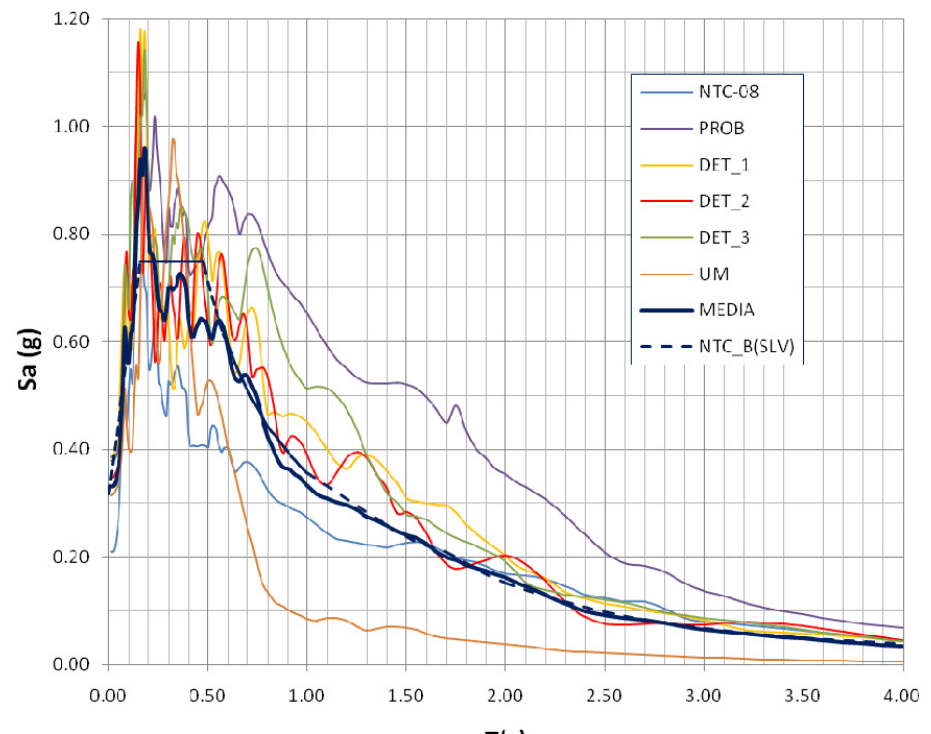

$T(s)$

Figure 6: Comparison of elastic acceleration response spectra obtained by site response analysis and according to NTC 2008 [14], for a return period $T_{\mathrm{R}}=475$ years and type $\mathrm{B}$ ground, at the site of Palazzo Camponeschi. 
marked peaks of $S_{\text {a }}$ concentrated within a very narrow range of periods $(T \approx$ $0.15-0.2 \mathrm{~s}$ ). At higher periods the average trend of $S_{\mathrm{a}}$ resulting from the site response analysis tends to become similar to the building code spectrum. In general, the NTC 2008 [14] simplified approach underestimates the seismic action calculated by site response analysis over the whole range of periods.

Table 1 summarizes the values obtained by the numerical analysis, for each of the six input accelerograms, of the peak ground horizontal acceleration $(P G A)$, the peak ground horizontal displacement $(P G D)$ and the Housner [15] spectral intensity $\left(I_{\mathrm{H}}\right)$, calculated from velocity response spectra in the range of periods 0.2 to $2 \mathrm{~s}$. The values of $P G A$ obtained from the site response analysis, mostly in the range $0.31-0.39 \mathrm{~g}$, are in agreement with the values $(0.33-0.35 \mathrm{~g}$ in horizontal direction) recorded during the April 6, 2009 main shock at the strong motion station $\mathrm{AQK}$, located in the city centre at $\approx 1 \mathrm{~km}$ distance, except the much lower $P G A=0.21 \mathrm{~g}$ calculated using the input accelerogram (NTC-08). Also, the $P G A$ calculated by the site response analysis is generally higher than the $P G A=0.30 \mathrm{~g}$ predicted by the Italian building code, for $T_{\mathrm{R}}=475$ years and type $\mathrm{B}$ ground. A similar agreement is observed between the values of horizontal $P G D$ calculated $(5.9-14.2 \mathrm{~cm})$ and recorded at AQK during the main shock $(7.65-12.50 \mathrm{~cm})$, except the lower $P G D=1.2 \mathrm{~cm}$ calculated using the input accelerogram (UM). The values of the Housner intensity $I_{\mathrm{H}}$ obtained from the site response analysis for the six input accelerograms vary from $0.50 \mathrm{~m}$ (UM) to $1.75 \mathrm{~m}$ (PROB) and, on average, are slightly higher than the values calculated from the main shock recording at AQK (1.07-1.09 $\mathrm{cm}$, Masi et al. [16]). The value calculated according to NTC $2008[14]$ is much lower $\left(I_{\mathrm{H}}=0.90 \mathrm{~m}\right)$.

Table 1: $\quad$ Peak ground horizontal acceleration $(P G A)$, peak ground horizontal displacement $(P G D)$ and Housner intensity $\left(I_{\mathrm{H}}\right)$ in the range of periods $T=0.2-2 \mathrm{~s}$ evaluated by site seismic response analysis at the site of Palazzo Camponeschi for six input accelerograms.

\begin{tabular}{|c|c|c|c|c|c|c|}
\hline & NTC-08 & PROB & DET_1 & DET_2 & DET_3 & UM \\
\hline$P G A(\mathrm{~g})$ & 0.21 & 0.39 & 0.39 & 0.35 & 0.38 & 0.31 \\
\hline$P G D(\mathrm{~cm})$ & 6.6 & 14.2 & 7.8 & 5.9 & 9.6 & 1.2 \\
\hline$I_{\mathrm{H}}(\mathrm{m})$ & 0.80 & 1.75 & 1.24 & 1.12 & 1.32 & 0.50 \\
\hline
\end{tabular}

\section{Site response analysis in the Pettino area}

\subsection{Input soil data}

The geotechnical model of the subsoil at the site of Via Sila Persichelli (Pettino), including the soil parameters used in the numerical analyses, is schematized in Figure 7. The model is composed of an upper soil layer of variable composition (clayey silt including cobbles), with $V_{\mathrm{S}}$ increasing from $\approx 300$ to $550 \mathrm{~m} / \mathrm{s}$, placed on the seismic bedrock $\left(V_{\mathrm{S}}=900 \mathrm{~m} / \mathrm{s}\right)$, located at $21 \mathrm{~m}$ depth. The profile of $V_{\mathrm{S}}$ was defined as an average of three $V_{\mathrm{S}}$ profiles obtained by SDMT in backfilled boreholes to $\approx 27-30 \mathrm{~m}$ depth (Figure 8 ). The upper soil layer was characterized by laboratory $G / G_{0}-\gamma$ and $D-\gamma$ curves obtained by resonant column/torsional 
shear tests carried out at the Politecnico di Torino on an undisturbed sample (S1C1), taken in a soil layer of similar characteristics, at $5 \mathrm{~m} \mathrm{depth,} \mathrm{in} \mathrm{the}$ C.A.S.E. Project site of Camarda (MS-AQ Working Group [2]).

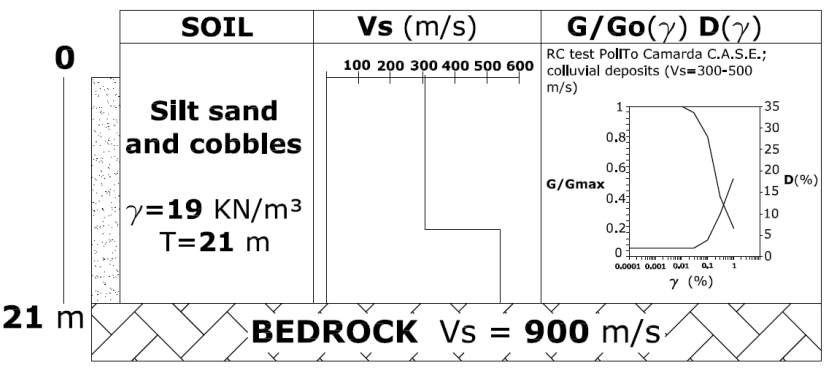

Figure 7: Geotechnical model of the subsoil and soil parameters for 1D seismic response analysis at the site of Via Sila Persichelli.

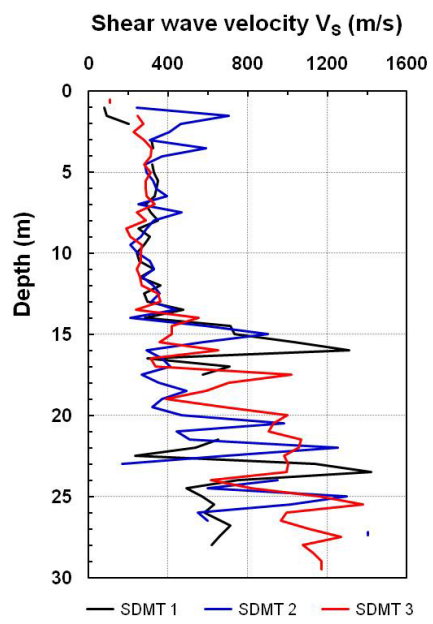

Figure 8: $\quad$ Profiles of shear wave velocity $V_{\mathrm{S}}$ obtained by SDMT (in backfilled boreholes) at the site of Via Sila Persichelli.

\subsection{Results and comparisons}

Figure 9 shows the comparison of the elastic acceleration response spectra resulting from the numerical analysis using six different input accelerograms, the corresponding average spectrum and the elastic response spectrum defined according to the simplified approach suggested by the Italian building code (NTC 2008 [14]), for a reference return period $T_{R}=475$ years (SLV) and type E ground. Figure 9 shows that the spectral acceleration $S_{\text {a }}$ calculated by the numerical analysis (average of the six input accelerograms) is generally higher than $S_{\text {a }}$ calculated according to NTC 2008 [14] in the range of periods $T \approx 0.2-0.6 \mathrm{~s}$. Also in this case marked peaks of $\mathrm{Sa}$ are observed, concentrated within the range of 
periods $T \approx 0.15-0.4 \mathrm{~s}$ (less narrow than in the city centre). The maximum amplitude of $\mathrm{Sa}$ is much higher than in the city centre. For $T>0.5 \mathrm{~s}$ the average trend of $S_{\mathrm{a}}$ resulting from the numerical analysis tends to become lower than the building code spectrum. Compared to the site response analysis results, the NTC 2008 [14] simplified approach seems to largely underestimate the seismic action at low periods and to overestimate it at high periods. A similar trend is observed, in Figure 9, even in comparison to the elastic response spectrum defined according to NTC (2008) [14] for a return period $T_{R}=975$ years (SLC).

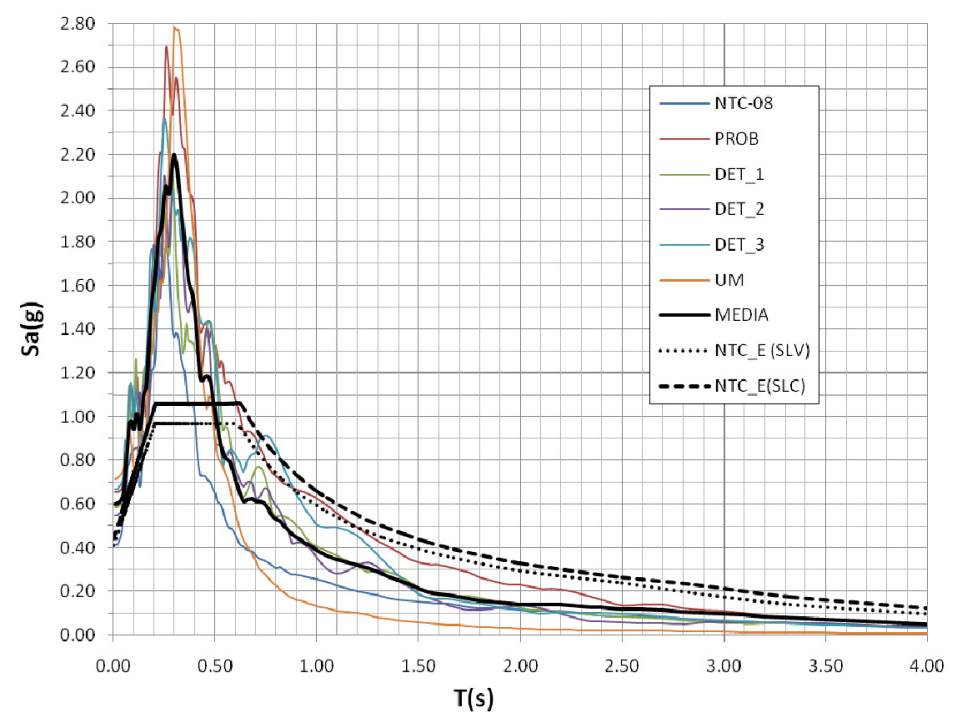

Figure 9: Comparison of elastic acceleration response spectra obtained by site response analysis and according to NTC 2008 [14], for return periods $T_{\mathrm{R}}=475$ years (SLV) and $T_{\mathrm{R}}=975$ years (SLC) and type E ground, at the site of Via Sila Persichelli.

Table 2 summarizes the values obtained by the numerical analysis, for each of the six input accelerograms, of the peak ground horizontal acceleration $(P G A)$, the peak ground horizontal displacement $(P G D)$ and the Housner intensity $\left(I_{\mathrm{H}}\right)$ calculated in the range of periods 0.2 to $2 \mathrm{~s}$. The values of $P G A=0.42-0.71 \mathrm{~g}$ calculated by the site response analysis are almost twice than the $P G A=0.21$ $0.39 \mathrm{~g}$ calculated in the city centre, and higher than $P G A=0.40 \mathrm{~g}$ (SLV) predicted

Table 2: $\quad$ Peak ground horizontal acceleration $(P G A)$, peak ground horizontal displacement $(P G D)$ and Housner intensity $\left(I_{\mathrm{H}}\right)$ in the range of periods $T=0.2-2 \mathrm{~s}$ evaluated by site seismic response analysis at the site of Via Sila Persichelli for six input accelerograms.

\begin{tabular}{|c|c|c|c|c|c|c|}
\hline & NTC-08 & PROB & DET_1 & DET_2 & DET_3 & UM \\
\hline$P G A(\mathrm{~g})$ & 0.42 & 0.42 & 0.59 & 0.55 & 0.67 & 0.71 \\
\hline$P G D(\mathrm{~cm})$ & 0.7 & 1.4 & 1.1 & 1.0 & 1.1 & 1.4 \\
\hline$I_{\mathrm{H}}(\mathrm{m})$ & 0.88 & 1.90 & 1.34 & 1.31 & 1.56 & 0.98 \\
\hline
\end{tabular}


by NTC 2008 [14]. In contrast, the values of $P G D=0.7-1.4 \mathrm{~cm}$ obtained from the site response analysis are considerably lower than $P G D=1.2-14.2 \mathrm{~cm}$ calculated in the city centre. The values of the Housner intensity $I_{\mathrm{H}}$ obtained from the site response analysis for the six input accelerograms vary in the range 0.88 to 1.90 $\mathrm{m}$ and are similar to $I_{\mathrm{H}}=0.5$ to $1.75 \mathrm{~m}$ calculated in the city centre.

\section{Conclusions}

The comparison of results of seismic response analyses at the two sites confirms that site effects, related to different subsoil conditions, played an important role in the observed non-uniform damage distribution due to the April 6, 2009 earthquake. The above results are in agreement with previous observations based on comparisons of strong motion recordings of main shock at different stations (e.g. Masi et al. [16]), as well as with results of the seismic microzonation of the area of L'Aquila (MS-AQ Working Group [2]).

In L'Aquila city centre, despite the peak ground horizontal acceleration is not particularly high (the values of $P G A=0.33-0.35 \mathrm{~g}$ recorded at the $\mathrm{AQK}$ station during the main shock were the lowest recorded in the epicentral area), the values of the Housner intensity and of the peak ground horizontal displacement $\left(I_{\mathrm{H}} \approx 1-1.10 \mathrm{~m}, P G D \approx 7-12 \mathrm{~cm}\right.$ measured at $\mathrm{AQK}$, Masi et al [16]) are similar to or higher than the values recorded at the stations where much higher $P G A$ were measured $(0.66 \mathrm{~g}$ at $\mathrm{AQV})$. In this case, as noted in previous studies, the $P G A$ alone appears a poor indicator of the damage potential of ground motion, while the Housner intensity $I_{\mathrm{H}}$ appears a more effective parameter to correlate the severity of ground motion to structural damage. Particularly in the city centre, characterized by an inversion of $V_{\mathrm{S}}$ with depth, the simplified approach based on elastic response spectra defined according to ground type $\left(V_{\mathrm{S}, 30}\right)$ of the Italian building code tends to underestimate the seismic action.

In the area of Pettino the site response analysis provided values of $P G A=$ $0.42-0.71 \mathrm{~g}$, almost twice than $P G A$ calculated in the city centre. This result is in agreement with the grade-3 microzonation map obtained by MS-AQ Working Group [2], where the Pettino district is classified as the zone of maximum amplification within the urban area of L'Aquila.

\section{References}

[1] GEER Working Group, Preliminary Report on the Seismological and Geotechnical Aspects of the April 62009 L'Aquila Earthquake in Central Italy. Report No. GEER-016, Ver. 2.0, Sept. 2009, www.geerassociation.org

[2] MS-AQ Working Group, Microzonazione sismica per la ricostruzione dell'area aquilana. Regione Abruzzo - Dipartimento della Protezione Civile, L'Aquila, 3 vol. \& Cd-rom, 2010.

[3] Marchetti, S., Monaco, P., Totani, G. \& Marchetti, D., In Situ Tests by Seismic Dilatometer (SDMT). From Research to Practice in Geotechnical Engineering, ASCE Geotech. Spec. Publ. No. 180, pp. 292-311, 2008. 
[4] Amoroso, S., Marchetti, D., Marchetti, S., Monaco, P., Totani, F. \& Totani, G., Site characterization by seismic dilatometer (SDMT) in the area of L'Aquila. Proc. Workshop "The Dynamic Interaction of Soil and Structure”, L'Aquila, 19 March 2010, Aracne editrice: Roma, 2011.

[5] Totani, G., Monaco, P., Marchetti, S. \& Marchetti, D., $V_{\mathrm{S}}$ measurements by seismic dilatometer (SDMT) in non-penetrable soils. Proc. $17^{\text {th }}$ ICSMGE, Alexandria, Egypt, IOS Press, 2, pp. 977-980, 2009.

[6] Amoroso, S., Del Monaco, F., Di Eusebio, F., Monaco, P., Taddei, B., Tallini, M., Totani, F. \& Totani, G., Campagna di indagini geologiche, geotecniche e geofisiche per lo studio della risposta sismica locale della città dell'Aquila: la stratigrafia dei sondaggi giugno-agosto 2010 . University of L'Aquila, Report CERFIS 1/10, 2010, www.cerfis.it

[7] De Luca, G., Marcucci, S., Milana, G. \& Sanò, T., Evidence of lowfrequency amplification in the city of L'Aquila, Central Italy, through a multi-disciplinary approach including strong- and weak-motion data, ambient noise, and numerical modeling. Bull. Seism. Soc. Am., 95(4), pp. 1469-1481, 2005.

[8] Bardet, J.P., Ichii, K. \& Linn, C.H., EERA - A Computer Program for Equivalent-linear Earthquake site Response Analyses of Layered Soil Deposits. University of Southern California, 2000.

[9] Chiara, N., Investigation of Small-Strain Shear Stiffness Measured in Field and Laboratory Geotechnical Studies. MS Thesis, Department of Civil Engineering, University of Texas at Austin, 2001.

[10] Crespellani, T., Ghinelli A., Vannucchi, G., An Evaluation of the Dynamic Shear Modulus of a Cohesive Deposit near Florence, Italy. Proc. XII ICSMFE, Rio de Janeiro, 1989.

[11] Cardarelli, E. \& Cercato, M., Relazione sulla campagna d'indagine geofisica per lo studio della Risposta Sismica Locale della città dell'Aquila. Prova crosshole sondaggi S3-S4. Report DICEA - University of Roma La Sapienza, 2010, www.cerfis.it

[12] Di Capua, G., Lanzo, G., Luzi, L., Pacor, F., Paolucci, R., Peppoloni, S., Scasserra, G. \& Puglia, R., Caratteristiche geologiche e classificazione di sito delle stazioni accelerometriche della RAN ubicate a L'Aquila. Report Progetto S4: Banca dati accelerometrica, 2009, http://esse4.mi.ingv.it

[13] Modoni, G. \& Gazzellone, A., Simplified theoretical analysis of the seismic response of artificially compacted gravels. V Int. Conf. on Recent Advances in Geotech. Earthquake Eng. and Soil Dyn., San Diego, Paper No. 1.28a, 2010.

[14] NTC 2008 - Norme Tecniche per le Costruzioni. (Italian Building Code).

[15] Housner, G.W., Spectrum Intensity of Strong-Motion Earthquakes. Proc. Symp. Earthquakes and Blast Effects on Structures, UCLA, pp. 20-36, 1952.

[16] Masi, A., Chiauzzi, L., Braga, F., Mucciarelli, M., Vona, M. \& Ditommaso, R., Peak and integral seismic parameters of L'Aquila 2009 ground motions: observed versus code provision values. Bull. Earthquake Eng., 9, pp. 139$156,2011$. 